\title{
Lead removal by using carbon nanotubes
}

A.A. Muataz*

Department of Chemical Engineering, Centre of Excellent in Nanotechnology, King Fahd University of Petroleum and Minerals, P.O. Box 5050, Dhahran-31261, Saudi Arabia

E-mail: motazali@kfupm.edu.sa

*Corresponding author

\section{Fettouhi}

Chemistry Department,

King Fahd University of Petroleum and Minerals, P.O. Box 5050, Dhahran-31261, Saudi Arabia

E-mail: fettouhi@kfupm.edu.sa

\section{A. Al-Mammum and N. Yahya \\ Department of Biotechnology Engineering, International Islamic University Malaysia, P.O. Box 10, 50728 Kuala Lumpur, Malaysia E-mail: mamun@iiu.edu.my}

\begin{abstract}
Exposure to lead $(\mathrm{Pb})$ can cause anemia, diseases of the liver and kidneys, brain damage and ultimately death. For these reasons, heavy metals must be removed as much as possible from water. The removal of $\mathrm{Pb}$ (II) ions from aqueous solution using carbon nanotubes (CNT) as the adsorbent was investigated. The effects of $\mathrm{pH}$ were studied at $25^{\circ} \mathrm{C}$. Batch mode adsorption study has revealed that the removal of $\mathrm{Pb}$ (II) ions was maximum $(85 \%$ removal) at $\mathrm{pH} 5$ and achieved $83 \%$ removal at $40 \mathrm{mg} / \mathrm{L}$ of CNTs. The adsorption continuously increased in the $\mathrm{pH}$ range of 3-5, beyond which the adsorption could not be carried out due to the precipitation of metal. This study was also supported by characterisation of CNTs using FESEM. The characterisation suggested that at acidic condition ( $\mathrm{pH}$ 5), the surfaces of CNTs are more aligned and well-integrated compared to CNTs at different pHs. Finally, it can be concluded that CNTs could be a potential adsorbent for the removal of $\mathrm{Pb}$ from wastewater.
\end{abstract}

Keywords: carbon nanotubes; CNT; lead; pH; water treatment.

Reference to this paper should be made as follows: Muataz, A.A., Fettouhi, M., Al-Mammum, A. and Yahya, N. (2009) 'Lead removal by using carbon nanotubes', Int. J. Nanoparticles, Vol. 2, Nos. 1/2/3/4/5/6, pp.329-338.

Biographical notes: Ali Atieh Muataz is an Assistant Professor at Department of Chemical Engineering and he is the Head of Carbon Nanotechnology Research Unit (CNRU) under the Centre of Excellent in Nanotechnology (CENT) at King Fahd University of Petroleum and Minerals (KFUPM). 
Mohammed Fettouhi is an Associate Professor at Chemistry Department at King Fahd University of Petroleum and Minerals (KFUPM).

Abdullah Al-Mamun is an Assistant Professor at Department of Biotechnology Engineering, Faculty of Engineering at International Islamic University Malaysia.

Noorahayu Yahya is a BSc student at Department of Biotechnology Engineering, Faculty of Engineering at International Islamic University Malaysia. 